\title{
MRI of focal cortical dysplasia
}

\author{
Horst Urbach $^{1}\left[\right.$ D Elias Kellner ${ }^{2} \cdot$ Nico Kremers $^{1} \cdot$ Ingmar Blümcke $^{3} \cdot$ Theo Demerath $^{1}$
}

Received: 16 October 2021 / Accepted: 17 November 2021 / Published online: 27 November 2021

(c) The Author(s) 2021

\begin{abstract}
Focal cortical dysplasia (FCD) are histopathologically categorized in ILAE type I to III. Mild malformations of cortical development (mMCD) including those with oligodendroglial hyperplasia (MOGHE) are to be integrated into this classification yet. Only FCD type II have distinctive MRI and molecular genetics alterations so far. Subtle FCD including FCD type II located in the depth of a sulcus are often overlooked requiring the use of dedicated sequences (MP2RAGE, FLAWS, EDGE) and/or voxel (VBM)- or surface-based (SBM) postprocessing. The added value of 7 Tesla MRI has to be proven yet.
\end{abstract}

Keywords Focal cortical dysplasia $\cdot$ MRI $\cdot$ Lesions

Focal cortical dysplasia (FCD) are the most commonly resected epileptogenic lesions in children and the third most common lesions in adults [1]. They are defined as inborn (developmental), localized regions of malformed cerebral cortex, and encompass a broad spectrum of histopathological (light-microscopical) abnormalities [2]:

In a three-tiered light-microscopical classification proposed by the ILAE, FCD type I is a malformation with abnormal cortical layering, either compromising the radial (FCD type Ia) or the tangential composition of the 6-layered neocortex (FCD type Ib). The combination of both variants is classified as FCD type Ic [2]. Note, however, that very recently, the existence of FCD type Ib and Ic has been questioned [3].

FCD type II is a malformation with disrupted cortical lamination and specific cytological abnormalities, which differentiates FCD type IIa (dysmorphic neurons without balloon cells) from FCD type IIb (dysmorphic neurons and balloon cells) [4]. In 2011, Blumcke et al. added a FCD type III as a FCD type I in combination with hippocampal sclerosis

Horst Urbach

horst.urbach@uniklinik-freiburg.de

1 Dept. of Neuroradiology, Medical Center - University of Freiburg, Breisacher Str. 64, 79106 Freiburg, Germany

2 Dept. of Medical Physics, Medical Center - University of Freiburg, Freiburg, Germany

3 Dept. of Neuropathology, University Hospital Erlangen, Friedrich-Alexander-University Erlangen-Nürnberg, Erlangen, Germany
(FCD type IIIa), with epilepsy-associated tumors (FCD type IIIb), adjacent to vascular malformations (FCD type IIIc), or in association with epileptogenic lesions acquired in early life (i.e., traumatic injury, ischemic injury, or encephalitis) (FCD type IIId) [2].

Note that the rare association between FCD type II with hippocampal sclerosis, tumors, or vascular malformations should not be regarded as FCD type III variant [2]. In addition to FCD defined as localized regions of malformed cerebral cortex so-called mild malformations of cortical development (mMCD) may cause epilepsy. In mMCD, the cortical architecture is intact, the cortex is absent of aberrant cells, but an excessive number of neurons in the molecular layer (type1) or the white matter (type 2) is found [4]. Mild malformation of cortical development with oligodendroglial hyperplasia (MOGHE) is another mild malformation of cortical development characterized by gray white matter blurring due to heterotopic neurons in the white matter and an increased number of normal-appearing oligodendroglial cells in the deep cortical and the juxtacortical white matter $[5,6]$.

Distinct molecular genetics alterations are so far confined to FCD type II; no consistent findings have been reported for mMCD or FCD I [7-9]. In FCD type II, mammalian target of rapamycin (mTOR) pathway mutations of genes within this pathway, including AKT1, AKT3, DEPDC5, MTOR, NPRL2/3, PIK3CA, PIK3R2, and TSC1/2 mutations, can be found [10-12].

On MRI, FCD features are an increased cortical thickness (60-91\% of FCD), a blurring of the gray/white matter 
junction (74-96\% of FCD), a transmantle sign (75\% of FCD type IIa, $94 \%$ of FCD type IIb), and/or an abnormal gyral/ sulcal pattern [13-18]. mMCD (type 2) can be characterized by a signal increase of the white matter with blurring of the gray/white matter junction (Table 1). In young children (up to 3 years), MOGHE typically shows a T2- and FLAIRhyperintense juxtacortical band (subtype I) (Fig. 3), which may represent hypomyelination. In older children, the band is not longer visible; instead, there is a reduced corticomedullary differentiation (subtype II) [6]

MRI abnormalities of FCD are often subtle and-as they usually do not change during life-often overlooked. The most overlooked lesion is a FCD in the depth of a sulcus (bottom of sulcus dysplasia) [19]. The transmantle sign - a funnel-shaped hyperintensity tapering towards the lateral ventricle-is only found in FCD type II $[13,17]$. It is suggestive of a FCD type IIb, but not present in all FCD type IIb $[10,17]$. The subtle abnormalities may be highlighted with specific MR sequences and postprocessing tools. In this review, we describe several strategies to enhance the visibility of FCD and correlate histopathological classifications and MRI findings.

\section{MRI protocols}

MRI protocols to evaluate patients with drug-resistant focal epilepsies are largely standardized [20-22] (Table 2).

Table 1 ILAE classification of FCD, molecular genetics, and MRI findings

\begin{tabular}{|c|c|c|c|}
\hline & Histology & Molecular genetics & MRI \\
\hline FCD Ia & Radial microcolumns & \multirow[t]{3}{*}{ None } & \multirow{3}{*}{$\begin{array}{l}\text { Not directly visible, but may show blurring } \\
\text { of the gray/ white matter junction due to } \\
\text { heterotopic U-fiber neurons }\end{array}$} \\
\hline FCD Ib & Tangential microcolumns & & \\
\hline FCD Ic & Radial and tangential microcolumns & & \\
\hline FCD IIa & Dysmorphic neurons & $\begin{array}{l}\text { mTOR pathway mutations ( } A K T 1, A K T 3 \text {, } \\
\text { DEPDC5, MTOR, NPRL2/3, PIK3CA, } \\
\text { PIK3R2, RHEB, TSC1/2) }\end{array}$ & $\begin{array}{l}\text { Increased cortical thickness, blurring of } \\
\text { the gray/white matter junction, abnormal } \\
\text { gyral/sulcal pattern }\end{array}$ \\
\hline FCD IIb & Dysmorphic neurons + balloon cells & & + transmantle sign ( $94 \%$ of patients) \\
\hline FCD IIIa & FCD I + hippocampal sclerois & \multirow[t]{4}{*}{ None } & $\begin{array}{l}\text { Not directly visible, but may show white } \\
\text { matter hypoplasia + white matter blurring }\end{array}$ \\
\hline FCD IIIb & FCD I+ epilepsy-associated tumors & & $?$ \\
\hline FCD IIIc & FCD I + vascular malformation & & $?$ \\
\hline FCD IIId & FCD I+ early life event & & $?$ \\
\hline mMCD 1 & $\begin{array}{l}\text { Ectopic neurons in molecular layer of } \\
\text { neocortex }\end{array}$ & \multirow[t]{2}{*}{ None } & $?$ \\
\hline mMCD 2 & Ectopic neurons in white matter & & May show white matter blurring \\
\hline MoGHE & $\begin{array}{l}\text { Increased number of oligodendroglial } \\
\text { cells + ectopic neurons in white matter }\end{array}$ & Mosaic $S L C 35 A 2$ variants & white matter blurring (in frontal lobe) \\
\hline
\end{tabular}

Table 2 Epilepsy-dedicated MRI protocol (3 T Magnetom Prisma, Siemens Healthcare, Erlangen, Germany)

\begin{tabular}{lllll}
\hline MRI sequence & $\begin{array}{l}\text { No. of slices/ } \\
\text { thickness }(\mathrm{mm})\end{array}$ & Voxel size $\left(\mathrm{mm}^{3}\right)$ & $\begin{array}{l}\text { TI/TR/TE/ } \alpha \\
\left(\mathrm{ms} / \mathrm{ms} / \mathrm{ms} /{ }^{\circ}\right)\end{array}$ & $\begin{array}{l}\text { Acquisition } \\
\text { time (min:s) }\end{array}$ \\
\hline sag 3D MPRAGE & $160 / 1$ & $1 \times 1 \times 1$ & $900 / 2000 / 2.26 / 12$ & $4: 40$ \\
sag 3D FLAIR-SPACE & $160 / 1$ & $1 \times 1 \times 1$ & $1800 / 5000 / 388 / \mathrm{var}$ & $6: 52$ \\
ax 2D T2-TSE & $42 / 3$ & $0.4 \times 0.4 \times 3$ & $5040 / 102 / 150$ & $4: 34$ \\
ax 2D T2* & $23 / 5$ & $0.7 \times 0.7 \times 5$ & $639 / 19.9 / 20$ & $2: 33$ \\
cor 2D T2-STIR & $40 / 2$ & $0.4 \times 0.4 \times 2$ & $100 / 5390 / 25 / 140$ & $8: 07$ \\
cor 2D FLAIR & $68 / 2$ & $0.7 \times 0.7 \times 2$ & $2500 / 9000 / 87 / 150$ & $4: 14$ \\
ax 2D DWI-SE EPI & $23 / 5$ & $0.6 \times 0.6 \times 5$ & $3400 / 85$ & $0: 46$ \\
sag 3D MP2RAGE & $192 / 1$ & $1 \times 1 \times 1$ & $700,5000 / 2000 / 2.9 / 4$ & $8: 52$ \\
\hline
\end{tabular}

MPRAGE magnetization prepared rapid gradient echo, FLAIR SPACE fluid-attenuated inversion recovery-sampling perfection with application-optimized contrasts by using flip angle evolution, TSE turbo spin echo, STIR short tau inversion recovery, $D W I$ diffusion-weighted imaging, $S E$ spin echo, EPI echo planar imaging, $T I$ inversion time, $T R$ repetition time, $T E$ echo time, $\alpha$ flip angle, var variable flip angle. 
Table 3 Overview of the results of various VBM and SBM tools

\begin{tabular}{llll}
\hline Study & Sequence & Method & Sensitivity, specificity \\
\hline Hong et al. 2014 & MPRAGE & SBM+ linear discriminant analysis & $0.74,1.00$ \\
Hong et al. 2017 & MPRAGE, 3D FLAIR, DTI & SBM+ linear discriminant analysis & n.a \\
Jin et al. 2018 & MPRAGE & SBM+CNN & $0.74,0.90$ AUC 0.75 \\
Wang et al. 2015 & MPRAGE & VBM: MAP & $0.9,0.67$ \\
David et al. 2021 & MPRAGE & VBM: MAP + CNN & $0.81,0.84$ \\
Sun et al. 2021 & MPRAGE & VBM: MAP & $0.43,0.87$ \\
Gill et al. 2021 & MPRAGE+3D FLAIR & SBM+CNN & $0.87,0.89$ \\
Demerath et al. 2021 & MP2RAGE & VBM: MAP + CNN & $0.82,0.34$ \\
\hline
\end{tabular}

\section{Key sequences}

Within a MRI protocol at 3 Tesla, the 3D fluid-attenuated inversion recovery (FLAIR) sequence named SPACE, CUBE, VISTA, or depending on the MR vendor is the most relevant MRI sequence for the visualization of epileptogenic lesions [21, 22]. Nulling of the CSF signal helps to improve the visibility of hyperintense cortical lesions [22]. Although 2D FLAIR sequences have a higher in-plane resolution and signal to noise ratio $(\mathrm{S} / \mathrm{N})$, 3D FLAIR sequences with isotropic $1 \mathrm{~mm}^{3}$ voxel are preferred as they allow for multiplanar reformations, which may include reformations along and perpendicular to the orientation of the FCD [20, 22, 23].

The magnetization-prepared rapid gradient-echo (MPRAGE) sequence and equivalent 3D spoiled gradient echo and 3D turbo field echo sequences with isotropic millimetric voxel resolution (e.g., $1 \times 1 \times 1 \mathrm{~mm}^{3}$ ) are other key sequences. These sequences allow not only for optimal evaluation of brain anatomy and morphology but are also used for voxel-based analysis including volumetry and postprocessing [24-31].

The MP2RAGE sequence is a MPRAGE sequence with two inversion pulses at $700 \mathrm{~ms}$ and $2500 \mathrm{~ms}$, respectively. From the two images, a so-called unified image is calculated using the formula MP2RAGE $=\frac{\text { contrastTI } 1 \times \text { contrastTI2 }}{\text { contrastT1 }^{2}+\text { contrastTI2 }^{2}}$ (Fig. 1).

The MP2RAGE sequence produces images with a higher $B_{1}$ homogeneity than the MPRAGE sequence and is therefore particularly suited for postprocessing [31-35]. The higher $B_{1}$ homogeneity is also the reason that 7 Tesla scanners are routinely equipped with this sequence [36-40].

The fluid and white-matter suppression (FLAWS) sequence is similar to the FLAIR sequence; however, not only the CSF but also the white matter signal is nulled. Two 3D sets with isotropic $1 \mathrm{~mm}^{3}$ voxel are acquired in an interleaved acquisition scheme with two different inversion times (TI): $\mathrm{TI}_{1}$ suppresses the white matter signal and $\mathrm{TI}_{2}$ suppresses the CSF signal. From both data sets, a set of synthetic minimum FLAWS contrast images is calculated which can be regarded as a gray matter specific image [41, 42] (Fig. 1).

The 3D Edge-Enhancing Gradient Echo sequence is a MPRAGE sequence with an inversion time of $442 \mathrm{~ms}$ [43]. At this inversion time, gray and white matter have equal signals but opposite phases and voxels with a mixture of gray and white matter (e.g., at the gray-white boundary) will have cancelation of longitudinal magnetization producing a thin area of signal void at the normal boundary (Fig. 1). Contrast to noise ratio $(\mathrm{C} / \mathrm{N})$ is reported to be higher than on MPRAGE and FLAIR sequences [43].

\section{Quantitative MRI sequences}

Quantitative MRI sequences measure tissue parameters such as the T1-, T2-, T2* relaxation times, or the proton density (PD) free from hardware-effects. However, they require the acquisition of several sequences including gradient echo sequences to correct for inhomogeneities of $\mathrm{B}_{0}$ and $\mathrm{B}_{1}$, and for insufficient spoiling of the transverse magnetization [44]. For T1and PD mapping, the variable flip angle method acquiring two spoiled gradient echo data sets at different flip angles is used [45]. A strategy for voxel-wise measurement of the T2 relaxation time is to acquire four fast spin echo datasets with different echo times (TEs), e.g., TE $=13,67$, 93, and $106 \mathrm{~ms}$. Mapping of both $\mathrm{T} 2 *$ and B0 inhomogeneities (to correct T1 data) is based on the acquisition of eight multiple-echo gradient echo (GE) datasets, e.g., 10, 16, 22, 28, 34, 40, 46, and $52 \mathrm{~ms}$ [46, 47]. Quantitative MRI sequences can be used to calculate synthetic magnetizationprepared rapid gradient-echo (MPRAGE) sequences which are-due to their high $\mathrm{B}_{1}$ field homogeneity — particularly suited for postprocessing.

3D MR fingerprinting (MRF) is another quantitative MRI technique. Acquired signals from a single $\approx 12 \mathrm{~min}$ $3 \mathrm{D}$ sequence with variable combinations of hundreds to thousands of TRs and flip angles are compared with those 
Fig. 1 FCD type IIb in the depth of the right superior frontal sulcus. A-C 3 Tesla axial, coronal, and sagittal 3D FLAIR SPACE images show a thickenend cortex and a hyperintense transmantle sign tapering towards the frontal horn of lateral ventricle $(\mathbf{B}, \mathbf{C}$ : arrow). D-F 3 Tesla sagittal MP2RAGE images at inversion times TI of $700 \mathrm{~ms}$ (D) and $2500 \mathrm{~ms}(\mathbf{E})$. Calculated so-called unified image $(\mathbf{F})$. G-I 3 Tesla sagittal FLAWS images at inversion times TI of $409 \mathrm{~ms} \mathrm{(G)}$ and $1160 \mathrm{~ms}$ (H). Calculated minimum intensity image (I). J 3 Tesla calculated sagittal EDGE image at an inversion time of $442 \mathrm{~ms}$ according to Bydder and Young (1995) and Hornak (2008). K-L MAP-postprocessed MP2RAGE images after inverse normalization and co-registration of the $\mathrm{CNN}$ output map to the unified images

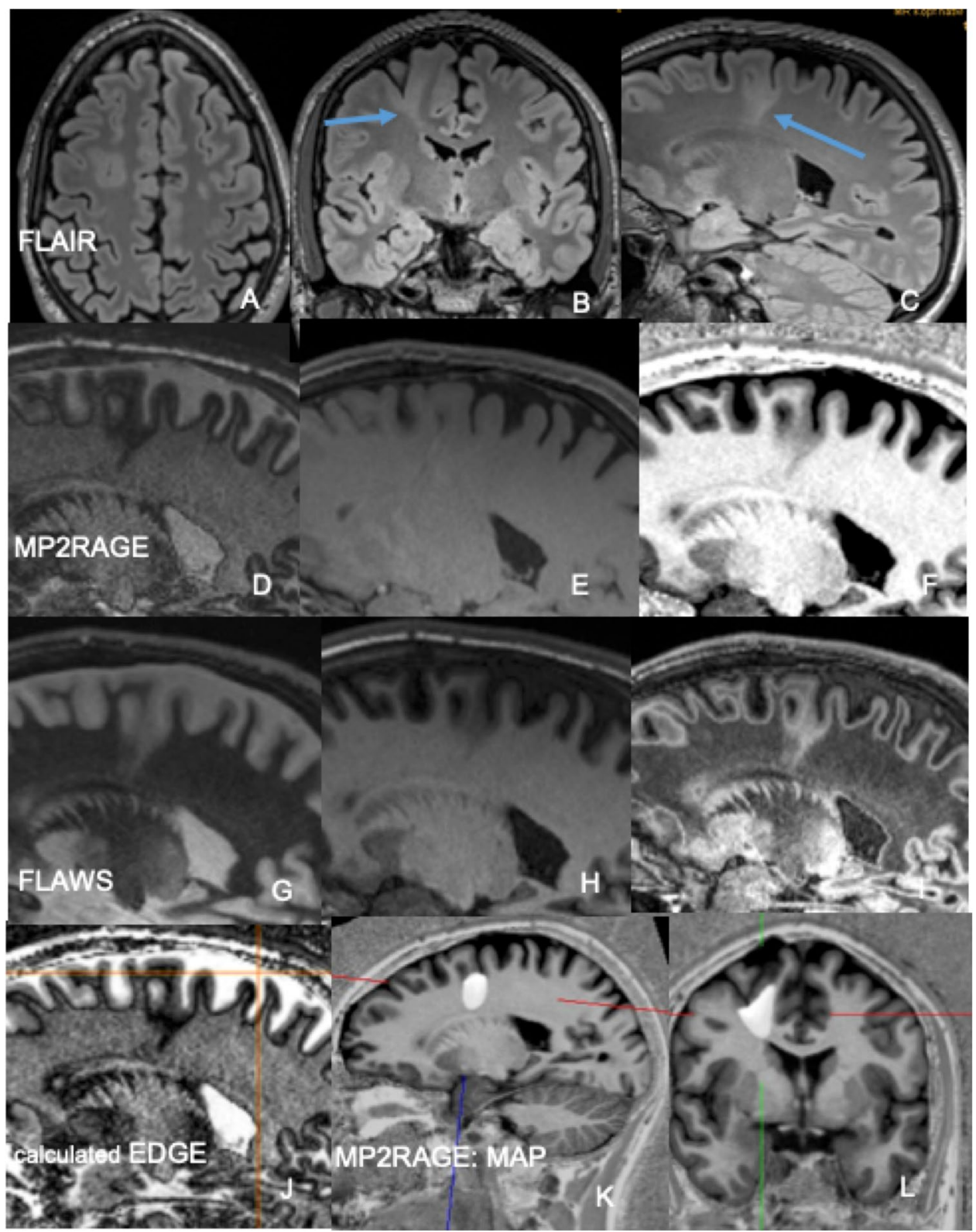

in a dictionary that contains signal evolutions from a wide range of physiologically relevant combinations of T1 and T2 [49). The acquired signal from each voxel is then assigned to the entry in the dictionary that best matches the signal evolution [47]. 3D MRF was reported to show additional information in 4 of 15 patients with FCD but is not in clinical routine yet [48].

\section{Postprocessing}

MRI features such as the cortical thickness, the gyral/sulcal pattern, or blurring of the gray/white matter junction can be computed semiautomatically using voxel-based (VBM) or surface-based morphometry (SBM). Texture analysis computing cubic volume sampling around each voxel to calculate second- and third-order textural features has also been described [49].

In a standard setting, T1-weighted data sets with $1 \times 1 \times 1$ $\mathrm{mm}^{3}$ are converted from DICOM to NIfTI format, undergo intensity non-uniformity correction, and are warped to a common template such as the MNI152 template. Other sequences, e.g., FLAIR, can be linearly mapped to the T1-weighted data sets. Next, gray matter (GM), white matter (WM), and CSF compartments are segmented.

For VBM, several feature maps (e.g., thickness, extension, junction maps in the MAP tool) are computed voxelwise [24]. For SBM, the gray/white matter boundary is tessellated and the folded surface tessellation inflated [28]. It allows for measuring the cortical thickness from 
its vertices and to calculate features such as intensity gradients within the cortex itself, but also features such as the gyral curvature, sulcal depth, or local cortical deformation [29, 50]. Most VBM and SBM algorithms however focus on the gray/white matter transition zone as the most prevalent feature of FCD. They compute features such as a smooth transition from the gray to the white matter. Features are typically analyzed with respect to a nominal distribution ( $z$ scores) requiring the use of data bases of healthy controls [24, 28, 51]. Machine learning tools with convolutional neural networks (CNN) are increasingly incorporated in VBM and SBM tools and trained with manually labeled ground-truth data to find FCD approaching accuracies of close to $90 \%$ so far $[25,28,31,35,52]$ (Figs. 1-2) (Table 3).

\section{Discussion}

Fifteen to $30 \%$ of patients with drug-resistant epilepsy are considered to be MRI negative; that is, no structural lesion is identified [53, 54]. However, MRI-negative is a misnomer. It comprises patients without a MRI lesion and those, in which a subtle MRI lesion, which however has a histopathological substrate, overlooked. Most overlooked lesion are FCD type 2; the rate is higher for FCD type IIa than type IIb [55]. The rate of overlooked lesions is likely around 30\% [28, 55-57], but may be as high as $41 \%$ or even $78 \%$ [25, 26, 58].

There is strong agreement that the visibility on MRI depends on the FCD type: FCD type II are visible on MRI provided adequate image quality on 3 Tesla machines and postprocessing is achieved. It has been reported that 7 Tesla is superior to 3 Tesla; however, post-processed 7
Fig. 2 A 24-year-old man with two FCD in the right cingulate gyrus. The anterior one with a transmantle sign was visually detected on a 3 Tesla 3D FLAIR sequence with isotropic $1 \mathrm{~mm}^{3}$ voxels (A, C-D: arrow). The posterior one was detected with the aid of the morphometric analysis program only $(\mathbf{B}, \mathbf{C}$, $\mathbf{E}$ hollow arrow, $\mathbf{F}$ crosshair on so-called junction image before first surgery, G-H crosshair on co-registered MP2RAGE and probability maps after second surgery). While the anterior lesion was classified as FCD $\mathrm{IIb}$, no FCD was diagnosed for the posterior lesion. As the patient did not get seizure-free the posterior lesionectony was extended and histology now revealed a FCD IIa

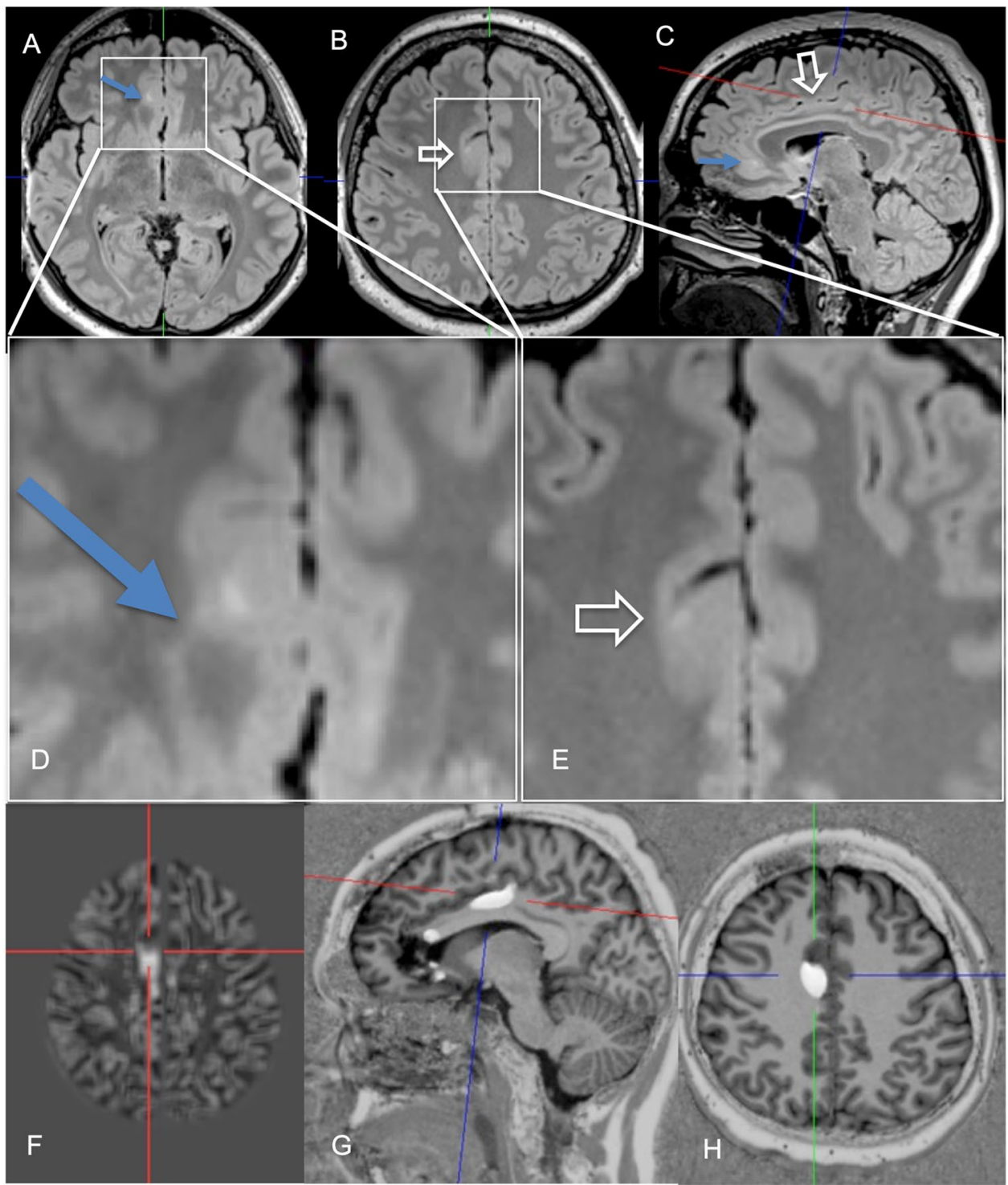


Tesla MP2RAGE images have been compared with 3 Tesla MPRAGE images [37, 38]. This comparison is biased as postprocessing using MP2RAGE images already displays FCD with larger volumes and higher $z$ scores [34].

There is limited agreement with respect to the visibility of FCD type I and III [22]. The abnormal arrangement of cortical neurons in FCD I and FCD III should not be visible on MRI as the cellular density is not changed [3]. However, the U-fiber layer beneath contains an excessive number of heterotopic neurons leading to a blurring of the gray/white matter junction. These displaced neurons form complex synaptic plexus within the U-fiber layer; some axons of which ascend into the cortex to be integrated into synaptic networks [59]. Mild malformation of cortical development with excessive white matter neurons (mMCD type 2 ) and with oligodendrogial hyperplasia (MOGHE) (Fig. 3) also produce a blurring of the gray/white matter junction on T2-weighted/ FLAIR sequences.

The difficult diagnosis of mMCD and FCD type I is also indicated by the low intra-rater agreement documented in a blinded classification of 26 specimens by eight neuropathologists. A significant agreement was reached for FCD type II only [60]. Furthermore, the microcolumnar organization of FCD type Ia resembles neuronal radial migration streams during corticogenesis $[61,62]$ and may result, therefore, from delayed or arrested maturation at midgestation [10]. This also holds true for the temporal pole abnormalities associated with hippocampal sclerosis which may be FCD type IIIa but also may show a reduced number of axons on diffusion-mesocopic imaging [63]. The reduced number of axons rather indicates a maturation disorder and not a FCD.

Correlation of histology and MRI is further impeded by a significant number of patients with MRI-visible FCD who get seizure-free following surgery but show unremarkable histopathology (so-called MRI-positive, histology-negative FCD) (Fig. 2). In these patients, a neuropathological sampling error is the most likely explanation for missing the diagnosis.

Postprocessing has dramatically improved the detection rate of FCD. Thus, it is recommended to use a postprocessing tool for every patient with a drug-resistant focal epilepsy.
Fig. 3 Mild malformation of cortical development with oligodendroglial hyperplasia (MOGHE) in the left frontal lobe in a 3-year-old girl. A-C 3 Tesla coronal 3D T2 SPACE (A), axial T2 TSE (B), coronal T1 MPRAGE (C), and axial T2 TSE (D) images. T2-weighted images show a juxtacortical hyperintense signal band $(\mathbf{A}-\mathbf{B}$, arrows), extending into the left precentral gyrus (B, arrowhead). On the MPRAGE image, the T2-hyperintense band looks like a subtle blurring of the gray-white matter junction $(\mathbf{C}$ arrows). D Axial T2w image after subtotal left frontal lobe resection. Despite residual lesion in the left precentral gyrus, the patient was seizurefree (Engel IA) after 3 months

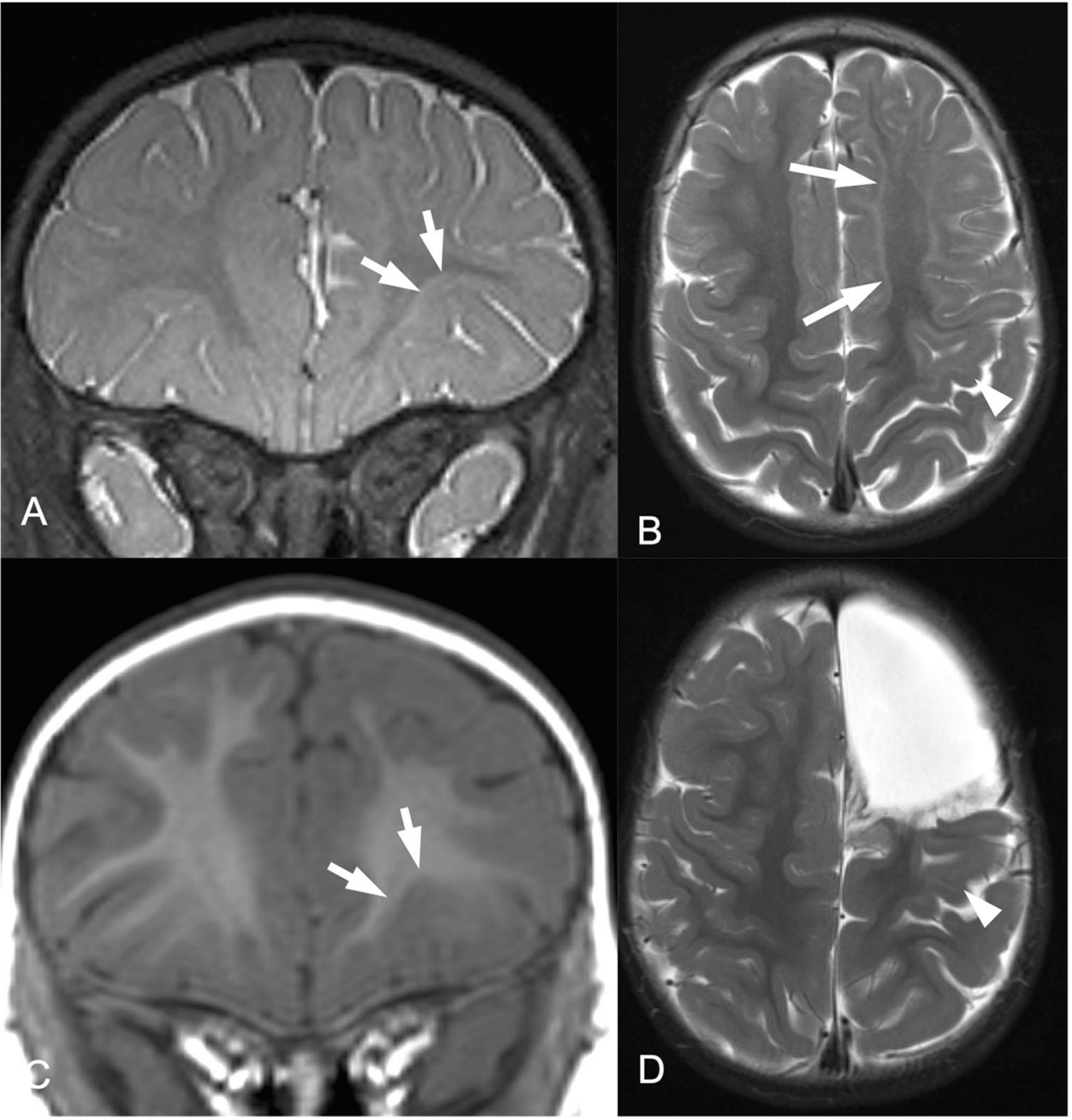


Among the different tools, the VBM tool morphometric analysis program (MAP) is the most widely used tool; it has been integrated in standard presurgical workflows of over 60 epilepsy centers in 22 different countries [35, 55, 64]. The MAP tool has independently been validated for its clinical benefits against expert neuroradiological assessments $[26,34,54$,] with potential impact on further, also invasive presurgical patient management [34, 57]. Surface-based (SBM) tools at least theoretically allow for a better analysis of the cortical layers itself; however, the superiority to VBM has not been shown yet $[20-30,51,65]$. Multiple standalone tools also processing multiple including quantitative sequences are currently being developed $[25,27,28,30,31$, $47,52,64,66]$. Which postprocessing tool will prevail is at the end also a matter of availability and ease of use [64].

Due to their higher $\mathrm{S} / \mathrm{N}$, which is theoretically proportional to the magnetic field strength $\mathrm{B}_{0}$, more FCD should be detectable on 7 Tesla compared to 3 Tesla scanners. In practice, however, stronger $B_{1}$ field inhomogeneities at 7 Tesla impede the detection of subtle signal differences especially at the gray/white matter junction. The higher susceptibility $\left(\chi \approx \mathrm{B}_{0}\right)$ improves the visibility of lesions with paramagnetic substances but also comes with more artifacts at brain interfaces to air-filled bony structures. Wang et al. published the largest comparative study so far, a prospective cohort of previously MRI-negative classified 67 patients [37]. They investigated the additional value of 7 T MAP using the MP2RAGE sequence and detected 25\% (6 of 24 patients) more lesions compared to $3 \mathrm{~T}$ MAP based on the MPRAGE sequence. As MP2RAGE images show a higher contrast and a higher contrast-to-noise ratio than MPRAGE images even at the same field strength, the meaningfulness is limited [34].

Current recommendations stress the technical challenges (use of dielectric pads to limit $\mathrm{B}_{1}$ field inhomogeneities, patient's discomfort including dizziness, longer scanning times, larger flip angle variations in 3D SPACE sequences, etc.) and suggest the use of 7 Tesla MRI to be confined to 3 Tesla negative cases [36, 39, 40, 67].

\section{Conclusion}

Albeit, there are standardized MRI protocols; FCD detection likely benefits from "newer" dedicated sequences (MP2RAGE, FLAWS, EDGE) and voxel- or surface-based postprocessing including the comparison with a data base of healthy controls. Only FCD type II have clear histopathological and MRI characteristics.

Author contribution Horst Urbach: data collection, editing, review of the manuscript.

Elias Kellne: data processing, review of the manuscript.
Nico Kremers: data collection, editing, review of the manuscript. Ingmar Blümcke: editing, review of the manuscript.

Theo Demerath: data collection, editing, review of the manuscript.

Funding Open Access funding enabled and organized by Projekt DEAL.

Data availability On reasonable request to corresponding author, the underlying data can be accessed.

\section{Declarations}

Ethics approval All procedures performed in the studies involving human participants were in accordance with the 1964 Helsinki Declaration and its later amendments.

Informed consent was obtained from all patients included in the study.

Conflict of interest The authors declare no competing interests.

Open Access This article is licensed under a Creative Commons Attribution 4.0 International License, which permits use, sharing, adaptation, distribution and reproduction in any medium or format, as long as you give appropriate credit to the original author(s) and the source, provide a link to the Creative Commons licence, and indicate if changes were made. The images or other third party material in this article are included in the article's Creative Commons licence, unless indicated otherwise in a credit line to the material. If material is not included in the article's Creative Commons licence and your intended use is not permitted by statutory regulation or exceeds the permitted use, you will need to obtain permission directly from the copyright holder. To view a copy of this licence, visit http://creativecommons.org/licenses/by/4.0/.

\section{References}

1. Blumcke I, Spreafico R, Haaker G, Coras R, Kobow K, Bien CG, Pfäfflin M, Elger C, Widman G, Schramm J, Becker A, Braun KP, Leijten F, Baayen JC, Aronica E, Chassoux F, Hamer H, Stefan H, Rössler K, Thom M, Walker MC, Sisodiya SM, Duncan JS, McEvoy AW, Pieper T, Holthausen H, Kudernatsch M, Meencke HJ, Kahane P, Schulze-Bonhage A, Zentner J, Heiland DH, Urbach H, Steinhoff BJ, Bast T, Tassi T, Lo Russo G, Özkara C, Oz B, Krsek $\mathrm{P}$, Vogelgesang S, Runge U, Lerche H, Weber Y, Honavar M, Pimentel J, Arzimanoglou A, Campos, AU, Noachtar S, Hartl E, Schijns O, Guerrini R, Barba C, Jacques TS, Cross HJ, Feucht M, Mühlebner A, Grunwald T, Trinka E, Winkler PA, Gil-Nagel A, Toledano Delgado R, Mayer T, Lutz M, Zountsas B, Garganis K, Rosenow F, Hermsen A, von Oertzen TJ, Diepgen TL, Avanzini $\mathrm{G}$, on behalf of the European Epilepsy Brain Bank (EEBB) Consortium (2017) Histopathological findings in brain tissue obtained during epilepsy surgery. N Engl J Med 377:1648-1656

2. Blumcke I, Thom M, Aronica E, Armstrong DD, Vinters HV, Palmini A, Jacques TS, Avanzini G, Barkovich AJ, Battaglia G, Becker A, Cepeda C, Cendes F, Colombo N, Crino P, Cross JH, Delalande O, Dubeau F, Duncan J, Guerrini R, Kahane P, Mathern G, Najm I, Ozkara C, Raybaud C, Represa A, Roper SN, Salamon N, Schulze-Bonhage A, Tassi L, Vezzani A, Spreafico R (2011) The clinico-pathological spectrum of Focal Cortical Dysplasias: a consensus classification proposed by an ad hoc Task Force of the ILAE Diagnostic Methods Commission. Epilepsia 52:158-174 
3. Coras R, Holthausen H, Sarnat HB (2021) Focal cortical dysplasia type 1. Brain Pathol 31(4):e12964. https://doi.org/10.1111/bpa. 12964

4. Palmini A, Najm I, Avanzini G, Babb T, Guerrini R, FoldvarySchaefer N, Jackson G, Luders HO, Prayson R, Spreafico R, Vinters HV (2004) Terminology and classification of the cortical dysplasias. Neurology 62:S2-8

5. Schurr J, Coras R, Rössler K, Pieper T, Kudernatsch M, Holthausen H, Winkler P, Woermann F, Bien CG, Polster T, Schulz R, Kalbhenn T, Urbach H, Becker A, Grunwald T, Huppertz HJ, Gil-Nagel A, Toledano R, Feucht M, Mühlebner A, Czech T, Blümcke I (2017) Mild malformation of cortical development with oligodendroglial hyperplasia in frontal lobe epilepsy: a new clinico-pathological entity Brain Pathol 27:26-35. https:// doi.org/10.1111/bpa.12347

6. Hartlieb T, Winkler P, Coras R, Pieper T, Holthausen H, Blümcke I, Staudt M, Kudernatsch M (2019) Age-related MR characteristics in mild malformation of cortical development with oligodendroglial hyperplasia and epilepsy (MOGHE). Epilepsy Behav 91:68-74. https://doi.org/10.1016/j.yebeh.2018.07.009

7. Najm IM, Sarnat HB, Blümcke I (2018) Review: the international consensus classification of focal cortical dysplasia - a critical update 2018. Neuropathol Appl Neurobiol 44:18-31. https://doi. org/10.1111/nan.12462

8. Kobow K, Ziemann M, Kaipananickal H, Khurana I, Mühlebner A, Feucht M, Hainfellner JA, Czech T, Aronica E, Pieper T, Holthausen H, Kudernatsch M, Hamer H, Kasper BS, Rössler K, Conti V, Guerrini R, Coras R, Blümcke I, El-Osta A, Kaspi A (2019) Genomic DNA methylation distinguishes subtypes of human focal cortical dysplasia. Epilepsia 60(6):1091-1103. https://doi.org/10.1111/epi.14934

9. Bonduelle T, Hartlieb T, Baldassari S, Sim NS, Kim SH, Kang HC, Kobow K, Coras R, Chipaux M, Dorfmüller G, Adle-Biassette H, Aronica E, Lee JH, Blumcke I (2021) Baulac S (2021) Frequent SLC35A2 brain mosaicism in mild malformation of cortical development with oligodendroglial hyperplasia in epilepsy (MOGHE). Acta Neuropathol Commun 9(1):3. https://doi.org/10. 1186/s40478-020-01085-3

10. Blumcke I, Cendes F, Miyata H, Thom M, Aronica E, Najm I (2021) Toward a refined genotype-phenotype classification scheme for the international consensus classification of Focal Cortical Dysplasia. Brain Pathol 31:e12956. https://doi.org/10. 1111/bpa.12956

11. Jesus-Ribeiro J, Pires LM, Melo JD, Ribeiro IP, Rebelo O, Sales F, Freire A, Melo JB (2021) Genomic and epigenetic advances in focal cortical dysplasia types I and II: a scoping review. Front Neurosci 14:580357. https://doi.org/10.3389/fnins.2020.580357

12. Guerrini R, Cavallin M, Pippucci E, Rosati A, Bisulli F, Dimartino P, Barba C, Garbelli R, Buccoliero AM, Tassi L, Conti V (2021) Is focal cortical dysplasia/epilepsy caused by somatic MTOR mutations always a unilateral disorder? Neurol Genet 7:e540. https:// doi.org/10.1212/NXG.0000000000000540

13. Urbach H, Scheffler B, Heinrichsmeier T, von Oertzen J, Kral T, Wellmer J, Schramm J, Wiestler OD, Blümcke I (2002) Focal cortical dysplasia of Taylor's balloon cell type: a clinicopathological entity with characteristic neuroimaging and histopathological features, and favorable postsurgical outcome. Epilepsia 43:33-40

14. Colliot O, Antel SB, Naessens VB, Bernasconi N, Bernasconi A (2006) In vivo profiling of focal cortical dysplasia on highresolution MRI with computational models. Epilepsia 47:134-142

15. Krsek P, Maton B, Korman B, Pacheco-Jacome E, Jayakar P, Dunoyer C, Rey G, Morrison G, Ragheb J, Vinters HV, Resnick T, Duchowny M (2008) Different features of histopathological subtypes of pediatric focal cortical dysplasia. Ann Neurol 63:758-769
16. Lerner JT, Salamon N, Hauptman JS, Velasco TR, Hemb M, Wu JY, Sankar R, Donald Shields W, Engel J Jr, Fried I, Cepeda C, Andre VM, Levine MS, Miyata H, Yong WH, Vinters HV, Mathern GW (2009) Assessment and surgical outcomes for mild type I and severe type II cortical dysplasia: a critical review and the UCLA experience. Epilepsia 50:1310-1335

17. Colombo N, Tassi L, Deleo F, Citterio A, Bramerio M, Mai R, Sartori I, Cardinale F, Lo Russo G, Spreafico R (2012) Focal cortical dysplasia type IIa and IIb: MRI aspects in 118 cases proven by histopathology. Neuroradiology 54:1065-1077

18. Wang ZI, Alexopoulos AV, Jones SE, Jaisani Z, Najm IM, Prayson RA (2013) The pathology of magnetic-resonance-imagingnegative epilepsy. Mod Pathol 26:1051-1058. https://doi.org/10. 1038/modpathol.2013.52 (Epub 2013 Apr 5)

19. Besson P, Andermann F, Dubeau F, Bernasconi A (2008) Small focal cortical dysplasia lesions are located at the bottom of a deep sulcus. Brain 131:3246-3255

20. Wellmer J, Quesada C, Rothe L, Elger CE, Bien CG, Urbach H (2013) Proposal for a magnetic resonance imaging protocol for the detection of epileptogenic lesions at early outpatient stages. Epilepsia 54:1977-1987

21. Urbach H, Mast H, Egger K, Mader I (2015) Presurgical MR imaging in epilepsy. Clin Neuroradiol 25:151-155

22. Bernasconi A, Cendes F, Theodore WH, Gill RS, Koepp MJ, Hogan RE, Jackson GD, Federico P, Labate A, Vaudano AE, Blümcke I, Ryvlin P, Bernasconi N (2019) Recommendations for the use of structural magnetic resonance imaging in the care of patients with epilepsy: a consensus report from the International League Against Epilepsy Neuroimaging Task Force. Epilepsia 60:1054-1068

23. Tschampa HJ, Urbach H, MalterSurges MR, Greschus S, Gieseke J (2015) Magnetic resonance imaging of focal cortical dysplasia : comparison of 3D and 2D fluid attenuated inversion recovery sequences at 3 T. Epilepsy Res 116:8-14

24. Huppertz HJ. Morphometric MRI analysis. In: Urbach H, ed. MRI in Epilepsy. Springer Berlin Heidelberg; 2013:73-84

25. Hong SJ, Kim H, Schrader D, Bernasconi N, Bernhardt BC, Bernasconi A (2014) Automated detection of cortical dysplasia type II in MRI-negative epilepsy. Neurology 83:48-55

26. Wang ZI, Jones SE, Jaisani Z, Najm IM, Prayson RA, Burgess RC, Krishnan B, Ristic A, Wong CH, Bingaman W, GonzalezMartinez JA, Alexopoulos AV (2015) Voxel-based morphometric magnetic resonance imaging (MRI) postprocessing in MRI-negative epilepsies. Ann Neurol 77:1060-1075

27. Hong SJ, Bernhardt BC, Caldairou B, Hall JA, Guiot MC, Schrader D, Bernasconi N, Bernasconi A (2017) Multimodal MRI profiling of focal cortical dysplasia type II. Neurology 88:734 742. https://doi.org/10.1212/WNL.0000000000003632

28. Jin B, Krishnan B, Adler S, Wagstyl K, Hu W, Jones S, Najm I, Alexopoulos A, Zhang K, Zhang J, Ding M, Wang S; Pediatric Imaging, Neurocognition, and Genetics Study, Wang ZI (2018) Automated detection of focal cortical dysplasia type II with surface-based MRI post-processing and machine learning. Epilepsia 59:982-992. https://doi.org/10.1111/epi.14064

29. Kim JS, Singh V, Lee JK, Lee JK, Lerch J, Ad-Dab'bagh Y, MacDonald D, Lee JM, Kim SI, Evans AC (2005) Automated 3-D extraction and evaluation of the inner and outer cortical surfaces using a Laplacian map and partial volume effect classification. Neuroimage 27:210-221

30. Ahmed B, Brodley CE, Blackmon KE, Kuzniecky R, Barash G, Carlson C, Quinn BT, Doyle W, French J, Devinsky O, Thesen T (2015) Cortical feature analysis and machine learning improves detection of "MRI-negative" focal cortical dysplasia. Epilepsy Behav 48:21-28 
31. Gill RS, Lee HM, Chaldairou B, Hong SJ, Barba C, Deleo F, D'Incerti L, Coelho VCM, Lenge M, Semmelroch M, Schrader D, Bartolomei F, Guye M, Schulze-Bonhage A, Urbach H, Cho KH, Cendes F, Guerrini R, Jackson G, Hogan RE, Bernasconi N, Bernasconi A. Automated Detection of Focal Cortical Dysplasia using deep learning: a multicenter validation study. Neurology. 2021 Sep 14:https://doi.org/10.1212/WNL.0000000000012698. https://doi.org/10.1212/WNL.0000000000012698. Online ahead of print.

32. Marques JP, Kober T, Krueger G, van der Zwaag W, Van de Moortele PF, Gruetter R (2010) MP2RAGE, a self bias-field corrected sequence for improved segmentation and T1-mapping at high field. Neuroimage 49:1271-1281

33. Tanner M, Gambarota G, Kober T, Krueger G, Erritzoe D, Marques JP, Newbould R (2012) Fluid and white matter suppression with the MP2RAGE sequence. J Magn Reson Imaging 35:1063-1070

34. Demerath T, Rubensdörfer L, Schwarzwald R, Schulze-Bonhage A, Altenmüller DM, Kaller C, Kober T, Huppertz HJ, Urbach H (2020) Morphometric MRI analysis: improved detection of focal cortical dysplasia using the MP2RAGE sequence. AJNR Am J Neuroradiol 41:1009-1014

35. Demerath T, Kaller CP, Heers M, Staack A, Schwarzwald R, Kober T, Reisert M, Schulze-Bonhage A, Huppertz HJ, Urbach H (2021) Comparison of T1 MPRAGE and MP2RAGE sequence based automatic detection of focal cortical dysplasias using artificial neural networks. Epilepsia in press

36. Burkett BJ, Fagan AJ, Felmlee JP, Black DF, Lane JI, Port JD, Rydberg CH, Welker KM (2021) Clinical 7-T MRI for neuroradiology: strengths, weaknesses, and ongoing challenges. Neuroradiology 63:167-177. https://doi.org/10.1007/s00234-020-02629-z

37. Wang I, Oh S, Blümcke I, Coras R, Krishnan B, Kim S, Coras R, Krishnan B, Kim S, McBride A, Grinenko O, Lin Y, Overmyer M, Aung TT, Lowe M, Larvie M, Alexopoulos AV, Bingaman W, Gonzalez-Martinez JA, Najm I, Jones SE (2020) Value of 7T MRI and post-processing in patients with nonlesional 3T MRI undergoing epilepsy presurgical evaluation. Epilepsia 61:2509-2520. https://doi.org/10.1111/epi.16682

38. Wang ZI, Oh S-H, Lowe M, Larvie M, Ruggieri P, Hill V, Statsevych V, Moon D, Lee J, Emch T, Bena J, Blümcke I, Bingaman W, Gonzalez-Martinez JA, Najm I, Jones SE (2021) Radiological and clinical value of 7T MRI for evaluating 3T-visible lesions in pharmacoresistant focal epilepsies. Front Neurol 12:591586. https://doi.org/10.3389/fneur.2021.591586

39. Opheim G, van der Kolk A, Markenroth Bloch K, Colon AJ, Davis KA, Henry TR, Jansen JFA, Jones SE, Pan JW, Rössler K, Stein JM, Strandberg MC, Trattnig S, Van de Moortele PF, Vargas MI, Wang I, Bartolomei F, Bernasconi N, Bernasconi A, Bernhardt B, Björkman-Burtscher I, Cosottini M, Das SR, Hertz-Pannier L, Inati S, Jurkiewicz MT, Khan AR, Liang S, Ma RE, Mukundan S, Pardoe H, Pinborg LH, Polimeni JR, Ranjeva JP, Steijvers E, Stufflebeam S, Veersema TJ, Vignaud A, Voets N, Vulliemoz S, Wiggins CJ, Xue R, Guerrini R (2020) Guye M (2021) 7T epilepsy task force consensus recommendations on the use of $7 \mathrm{~T}$ MRI in clinical practice. Neurology 96(327-341):22. https://doi. org/10.1212/WNL.0000000000011413.Epub

40. van Lanen RHGJ, Colon AJ, Wiggins CJ, Hoeberigs MC, Hoogland G, Roebroeck A, Ivanov D, Poser BA, Rouhl RPW, Hofman PAM, Jansen JFA, Backes W, Rijkers K, Schijns OEMG (2021) Ultra-high field magnetic resonance imaging in human epilepsy: a systematic review. Neuroimage Clin. 30:102602 https://doi.org/ 10.1016/j.nicl.2021.102602. Online ahead of print.

41. Chen X, Qian T, Kober T, Zhang G, Ren Z, Yu T, Piao Y, Chen N, Li K (2018) Gray-matter-specific MR imaging improves the detection of epileptogenic zones in focal cortical dysplasia: a new sequence called fluid and white matter suppression (FLAWS). NeuroImage Clin 20:388-397

42. Sun K, Yu T, Yang D, Ren Z, Qiao L, Ni D, Wang X, Zhao Y, Chen X, Xiang J, Chen N, Gao R, Yang K, Lin Y, Kober T, Zhang G (2021) Fluid and white matter suppression imaging and voxelbased morphometric analysis in conventional magnetic resonance imaging-negative epilepsy. Front Neurol 12:651592. https://doi. org/10.3389/fneur.2021.651592

43. Middlebrooks EH, Kin C, Westerhold E (2020) Improved detection of focal cortical dysplasia using a novel 3D imaging sequence: Edge-Enhancing Gradient Echo (3D-EDGE) MRI. NeuroImage Clin 28:102449

44. Preibisch C, Deichmann R (2009) Influence of RF spoiling on the stability and accuracy of T1 mapping based on spoiled FLASH with varying flip angles. Magn Reson Med 61:125-135. https:// doi.org/10.1002/mrm. 21776

45. Nöth U, Gracien RM, Maiworm M, Reif PS, Hattingen E, Knake S, Wagner M, Deichmann R (2020) Detection of cortical malformations using enhanced synthetic contrast images derived from quantitative T1 maps. NMR Biomed 33:e4203. https://doi.org/10. $1002 / \mathrm{nbm} .4203$

46. Seiler A, Schöngrundner S, Stock B, Nöth U, Hattingen E, Steinmetz H, Klein JC, Baudrexel S, Wagner M, Deichmann R, Gracien RM (2020) Cortical aging - new insights with multiparametric quantitative MRI. Aging (Albany NY) 12:16195-16210

47. Maiworm M, Nöth U, Hattingen E, Steinmetz H, Knake S, Rosenow F, Deichmann R, Wagner M, Gracien RM (2020) Improved visualization of focal cortical dysplasia with surface-based multiparametric quantitative MRI. Front Neurosci 14:622

48. Ma D, Jones SE, Deshmane A, Sakaie K, Pierre EY, Larvie M, McGivney D, Blümcke I, Krishnan B, Lowe M, Gulani V, Najm I, Griswold MA, Wang ZI (2019) Development of high-resolution 3D MR fingerprinting for detection and characterization of epileptic lesions. J Magn Reson Imaging 49:1333-1346. https://doi. org/10.1002/jmri.26319

49. Bernasconi A (2004) Quantitative MR imaging of the neocortex. Neuroimaging Clin N Am 14:425-436

50. House PM, Holst B, Lindenau M, Lindenau M, Voges B, Kohl B, Martens T, Lanz M, Stodieck S, Huppertz HJ (2015) Morphometric MRI analysis enhances visualization of cortical tubers in tuberous sclerosis. Epilepsy Res 117:29-34. https://doi.org/10. 1016/j.eplepsyres.2015.08.002

51. Kini LG, Gee JC, Litt B (2016) Computational analysis in epilepsy neuroimaging: a survey of features and methods. NeuroImage Clin 11:515-529. https://doi.org/10.1016/j.nicl.2016.02.013

52. David B, Kröll-Seger J, Schuch F, Wagner J, Wellmer J, Woermann F, Oehl B, Van Paesschen W, Breyer T, Becker A, Vatter H, Hattingen E, Urbach H, Weber B, Surges R, Elger CE, Huppertz HJ, Rüber T (2021) External validation of automated focal cortical dysplasia detection using morphometric analysis. Epilepsia 62:1005-1021. https://doi.org/10.1111/epi.16853

53. Bien CG, Raabe AL, Schramm J, Becker A, Urbach H, Elger CE (2009) Characteristics and surgical outcomes of patients with refractory magnetic resonance imaging-negative epilepsies. Arch Neurol 66:1491-1499

54. Duncan JS, Winston GP, Koepp MJ, Ourselin S (2016) Brain imaging in the assessment for epilepsy surgery. Lancet Neurol 15:420-433

55. Wagner J, Weber B, Urbach H, Elger CE, Huppertz HJ (2011) Morphometric MRI analysis improves detection of focal cortical dysplasia type II. Brain 134:2844-2854

56. Blümcke I, Coras R (2015) Histopathology findings in MRI-negative focal epilepsy In: MRI-negative epilepsy So EL Ryvelin P (editors). Cambridge University Press 19: 214-222

57. El Tahry R, Santos SF, Vrielynck P, de Tourtchaninoff M, Duprez T, Vaz GR, Raftopoulos C, Choi JY, Wang ZI (2020) Additional 
clinical value of voxel-based morphometric MRI post-processing for MRI-negative epilepsies: a prospective study. Epileptic Disord 22:156-164

58. Sarnat HB, Hader W, Flores-Sarnat L (2018) Bello-Espinosa L (2018) Synaptic plexi of U-fibre layer beneath focal cortical dysplasias: role in epileptic networks. Clin Neuropathol 37(6):262-276

59. Delev D, Oehl B, Steinhoff BJ, Nakagawa J, Scheiwe C, SchulzeBonhage A, Zentner J (2019) Surgical treatment of extratemporal epilepsy: results and prognostic factors. Neurosurgery 84:242-252

60. Chamberlain WA, Cohen ML, Gyure KA, Kleinschmidt-DeMasters BK, Perry A, Powell SZ, Qian J, Staugaitis SM, Prayson RA (2009) Interobserver and intraobserver reproducibility in focal cortical dysplasia (malformations of cortical development). Epilepsia 50:2593-2598

61. Mountcastle VB (1997) The columnar organization of the neocortex. Brain 120:701-722

62. Rakic P (1988) Specification of cerebral cortical areas. Science 241:170-176

63. Demerath T, Donkels C, Reisert M, Heers M, Rau A, Schröter N, Schulze-Bonhage A, Reinacher P, Scheiwe C, Shah MJ, Beck J, Vlachos A, Haas CA, Urbach H (2021) Gray-white matter blurring of the temporal pole associated with hippocampal sclerosis: a microstructural study involving 3T MRI and ultrastructural histopathology. Cereb Cortex. 2021 Sep 13:bhab320. https://doi. org/10.1093/cercor/bhab320

64. Urbach H, Heers M, Altenmueller DM, Schulze-Bonhage A, Staack AM, Bast T, Reisert M, Schwarzwald R, Kaller CP, Huppertz HJ, Demerath T (2021) "Within a minute" detection of focal cortical dysplasia (FCD). Neuroradiology. 2021 Oct 9. https://doi. org/10.1007/s00234-021-02823-7. Online ahead of print.

65. Adler S, Lorio S, Jacques TS, Benova B, Gunny R, Cross JH, Baldeweg T, Carmichael DW (2017) Towards in vivo focal cortical dysplasia phenotyping using quantitative MRI. NeuroImage Clin 15:95-105

66. Ma D, Gulani V, Seiberlich N, Liu K, Sunshine JL, Duerk JL, Griswold MA (2013) Magnetic resonance fingerprinting. Nature 495:187-192

67. Kotikalapudi R, Martin P, Erb M, Scheffler K, Marquetand J, Bender B, Focke NK (2019) MP2RAGE multispectral voxel-based morphometry in focal epilepsy. Hum Brain Mapp 40:5042-5055

Publisher's note Springer Nature remains neutral with regard to jurisdictional claims in published maps and institutional affiliations. 